\title{
Effectiveness of Internet-Based Interventions on Glycemic Control in Patients With Type 2 Diabetes: Meta-Analysis of Randomized Controlled Trials
}

Ying Shen ${ }^{1}$, BS; Fengbin Wang ${ }^{1,2}$, MM; Xing Zhang ${ }^{1}$, MB; Xiaorou Zhu ${ }^{1}$, MB; Qiudan Sun $^{3}$, MA; Edwin Fisher ${ }^{4}$, $\mathrm{BA}, \mathrm{PhD}$; Xinying $\mathrm{Sun}^{1}, \mathrm{PhD}$

\footnotetext{
${ }^{1}$ School of Public Health, Peking University Health Science Center, Beijing, China

${ }^{2}$ Department of Health and Education, Beijing Municipal Commission of Health and Family Planning, Beijing, China

${ }^{3}$ Institute for Medical Humanities, Peking University Health Science Center, Beijing, China

${ }^{4}$ Gillings School of Global Public Health, University of North Carolina, North Carolina, NC, United States
}

\section{Corresponding Author:}

Xinying Sun, $\mathrm{PhD}$

School of Public Health

Peking University Health Science Center

38, Xueyuan Road

Haidian District, Beijing, China

Beijing, 100191

China

Phone: 868613691212050

Fax: 86861082801743

Email:xysun@bjmu.edu.cn

\section{Abstract}

Background: The popularity of internet as an area of research has grown manifold over the years. Given its rapid development and increasing coverage worldwide, internet-based interventions seem to offer a promising option to ameliorate huge burdens brought by type 2 diabetes mellitus. However, studies conducted by different researchers have provided contradictory results on the effect of internet-based interventions in glycemic control.

Objective: This meta-analysis aims to summarize currently available evidence and evaluate the overall impact of internet-based interventions on glycemic management of type 2 diabetic patients.

Methods: A systematic literature search was performed in PubMed, ScienceDirect, and Web of Science. Randomized controlled trials that used glycosylated hemoglobin values as the outcome measure of glycemic control were considered. Risk of bias and publication bias were evaluated.

Results: Of the 492 studies, 35 were included in meta-analysis, and results indicated that the weighted mean difference (WMD) between usual care and internet-based interventions at endpoint was $-0.426 \%$ (95\% CI -0.540 to $-0.312 ; P<.001$ ). Subgroup analyses revealed that intervention duration $\leq 3$ months yielded optimal performance (WMD $-0.51 \%$; $95 \%$ CI -0.71 to -0.31 ; $P<.001)$. Combined mobile and website interventions were substantially superior to solely Web-based and mobile-based interventions in glycemic control (combined WMD $-0.77 \%, 95 \%$ CI -1.07 to $-0.47 ; P<.001$; Web only: WMD $-0.48 \%$; $95 \%$ CI -0.71 to $-0.24, P<.001$; mobile only WMD $-0.31 \%, 95 \%$ CI -0.49 to $-0.14 ; P<.001)$. Furthermore, the effect of interventions with automated feedbacks was similar to those with manual feedbacks, and studies with internet-based educational contents were more effective in glycemic control. The assessment revealed a low risk of bias.

Conclusions: In conclusion, utilization of internet-based intervention is beneficial for patients with type 2 diabetes mellitus, and taking full advantage of this type of intervention may substantially reduce the incidence of complications and improve quality of life.

Trial Registration: International Prospective Register of Systematic Reviews (PROSPERO): CRD42017058032; https://www.crd.york.ac.uk/PROSPERO/display_record.php?RecordID=58032 (Archived by WebCite at http://www.webcitation.org/6yY7eQNHr) 
(J Med Internet Res 2018;20(5):e172) doi: 10.2196/jmir.9133

\section{KEYWORDS}

internet; type 2 diabetes mellitus; HbA1c; randomized controlled trial; meta-analysis

\section{Introduction}

With increasing prevalence and serious chronic and acute complications, diabetes has brought enormous burden to people's living and production. Glycemic control is vital in disease management as hyperglycemia and hypoglycemia can both lead to serious clinical consequences. However, in some areas, health care providers can only obtain patients' information on glycemic control and lifestyle during their consultation with a doctor, which is probably infrequent because of various reasons, such as patients' economic issues, educational levels, health awareness, and remote distance to health care centers. Hence, information obtained by doctors cannot comprehensively reflect patients' health status and may lead to suboptimal health decisions [1]. Therefore, most of the impetus of disease management is on the patients as diabetes is a life-course chronic condition, and health care providers cannot possibly accompany patients all the time [2]. As a result, to achieve wide-scale promotion of diabetes self-management, it is essential to explore an efficient, easily available, and cost-effective approach to bridge geographical and economic gaps and reach broader populations. Given the rapid development of new technology and penetration of internet in people's daily life, integrating diabetic inventions into existing technologies may have important implications and accord with clinical guidelines as they have widely referred to the significance of self-management and patients' education in diabetes control [3-5]. In this aspect, internet-based interventions perfectly meet the requirement, as they can not only easily reach the global population but also serve as a medium of mass information exchange [6].

Currently, many studies have explored the efficacy of using internet-based interventions in diabetes management. However, there is not a universally acknowledged verdict on whether internet-based interventions could make a significant difference in patients' glycemic level. Some research reported that compared with usual care, internet-based interventions could significantly reduce glycated hemoglobin $\left(\mathrm{HbA}_{1 \mathrm{c}}\right)$ levels in patients with type 2 diabetes mellitus (T2DM) [7-11], whereas others reported otherwise [12-16]. Therefore, to comprehensively evaluate the overall impact of internet-based interventions, a meta-analysis is needed to achieve the pooled result. Furthermore, to our best knowledge, although there were some meta-analyses studying the effect of internet-based interventions on diabetes management, most of them just looked at a single form such as mobile apps and few conducted a comprehensive comparison between different forms of internet-based interventions. As a result, by analyzing relevant randomized controlled trials (RCTs) on this issue, this meta-analysis aims to evaluate the feasibility and efficacy of internet-based interventions on diabetes management and hopes to discover the most effective model of intervention that will benefit as many patients as possible.
This meta-analysis was registered at the international prospective register of systematic reviews (no. CRD42017058032).

\section{Methods}

\section{Data Sources and Searches}

For this meta-analysis, we have conducted a search in PubMed, Web of Science, and ScienceDirect to identify studies relevant to this topic from their beginning to January 16, 2017. Keywords used in this search were "T2DM," "type 2 diabetes," "social media," "e-learning," "new media," "m-health," "mHealth," "internet-based," "web-based," "twitter," "eHealth," "e-health," "Facebook," "computer-delivered," "social web," "social software," "online case-based learning," "mobile learning," "digital game-based learning," "serious games," "wearable devices," "mobile app," "mobile application," and "smart phone-based." To achieve a searching scope that was broad enough, the above-mentioned keywords were not enclosed. In PubMed, we searched in all fields and found 291 papers. In both of Web of Science and ScienceDirect, we searched in title, abstracts and keywords and retrieved 228 and 65 papers, respectively. The language of studies was not limited.

To extend our search scope and include more studies in this field, we also manually searched the reference lists of several systematic reviews and meta-analyses that might be related to our own study [6,17-23]. The number of studies identified in this way was 76. Furthermore, in the process of records screening, we found that 1 study was built on a previously published research conducted by the same research group, which examined the efficacy of improvement made to the previous program and evaluated people's acceptance. As a result, the study of the previous research was also found through the reference list and was included. Therefore, a total of 77 studies were retrieved from the references lists of other research. After the removal of duplicates, 492 records were identified in total. Multimedia Appendix 1 shows details of search syntax.

\section{Study Selection}

Two reviewers, Shen and Wang, independently reviewed abstracts and full-text papers. Study selection was strictly based on uniform inclusion and exclusion criteria. The exclusion reason for each study was recorded, and in the case of disagreement, Sun was consulted, and discussion was held until a consensus was reached. Studies were included if they were RCTs, assessed patients aged older than 18 years with T2DM, compared the effect of internet-based interventions in glycemic management with a control group (CG) of usual care, and reported means and $\mathrm{SDs}$ of $\mathrm{HbA}_{1 \mathrm{c}}$ values for intervention group (IG) and CG both at baseline and endpoint or other relevant data from which mean and SD of $\mathrm{HbA}_{1 \mathrm{c}}$ could be calculated. If information on diabetes type was not clear, studies with the mean age of patients older than 30 years were included as there is a high possibility that they have T2DM [24]. Studies were 
excluded if they were nonrandomized, reviews, protocols, case reports, or commentaries; did not use $\mathrm{HbA}_{1 \mathrm{c}}$ as the outcome measure or there was an incomplete report of $\mathrm{HbA}_{1 \mathrm{c}}$; or included patients with type 1 diabetes or gestational diabetes. Furthermore, we also excluded studies that were not predominantly internet-based or the internet was only used as a supporting or additional tool to intensify the effect of other interventions, as it was difficult to tell whether the study effect was attributable to the internet or the other intervention. Interventions that purely used the mobile phone as a tool to send text messages were also excluded, as this was not internet-based. Moreover, to compare the effect of internet-based interventions with usual care, the $\mathrm{CG}$ should use usual care rather than internet-based interventions.

On the basis of retrieved abstracts, we excluded 398 records. We further examined the full texts of the remaining 94 studies, and 59 studies were excluded. A total of 25 studies did not provide data on $\mathrm{HbA}_{1 \mathrm{c}}$ or provided incomplete data on $\mathrm{HbA}_{1 \mathrm{c}}$; 15 studies also studied patients with T1DM; 7 studies used internet-based intervention in CG; interventions in 5 studies were designed for health professionals and still depended on face-to-face interactions; 12 studies reported results of the same 6 interventions, respectively, and thus 6 were excluded; and in 1 study, only $46.1 \%$ of patients $(n=511)$ used the internet at least monthly; therefore, the research group decided to send participants paper versions of their medical record and ask them to bring it during the next hospital visit. Therefore, as this research was largely not internet-based, it was also excluded (Figure 1).

\section{Data Extraction and Quality Assessment}

The following data in 35 studies were extracted using a standardized spreadsheet: the first author, year of publication, participants included (CG and IG, respectively), patients' characteristics (including attrition, completion rate, mean age, body mass index [BMI], and gender ratio), study design, intervention duration, study location, intervention method, $\mathrm{HbA}_{1 \mathrm{c}}$ data (including values at baseline and endpoint), and other useful information. Furthermore, studies included were numbered from 1 to 35 . One study had 2 IGs that met the eligibility criteria and was numbered $12 \mathrm{a}$ and $12 \mathrm{~b}$.

Figure 1. Flowchart of study selection. RCT: randomized controlled trials; T2DM: type 2 diabetes mellitus.

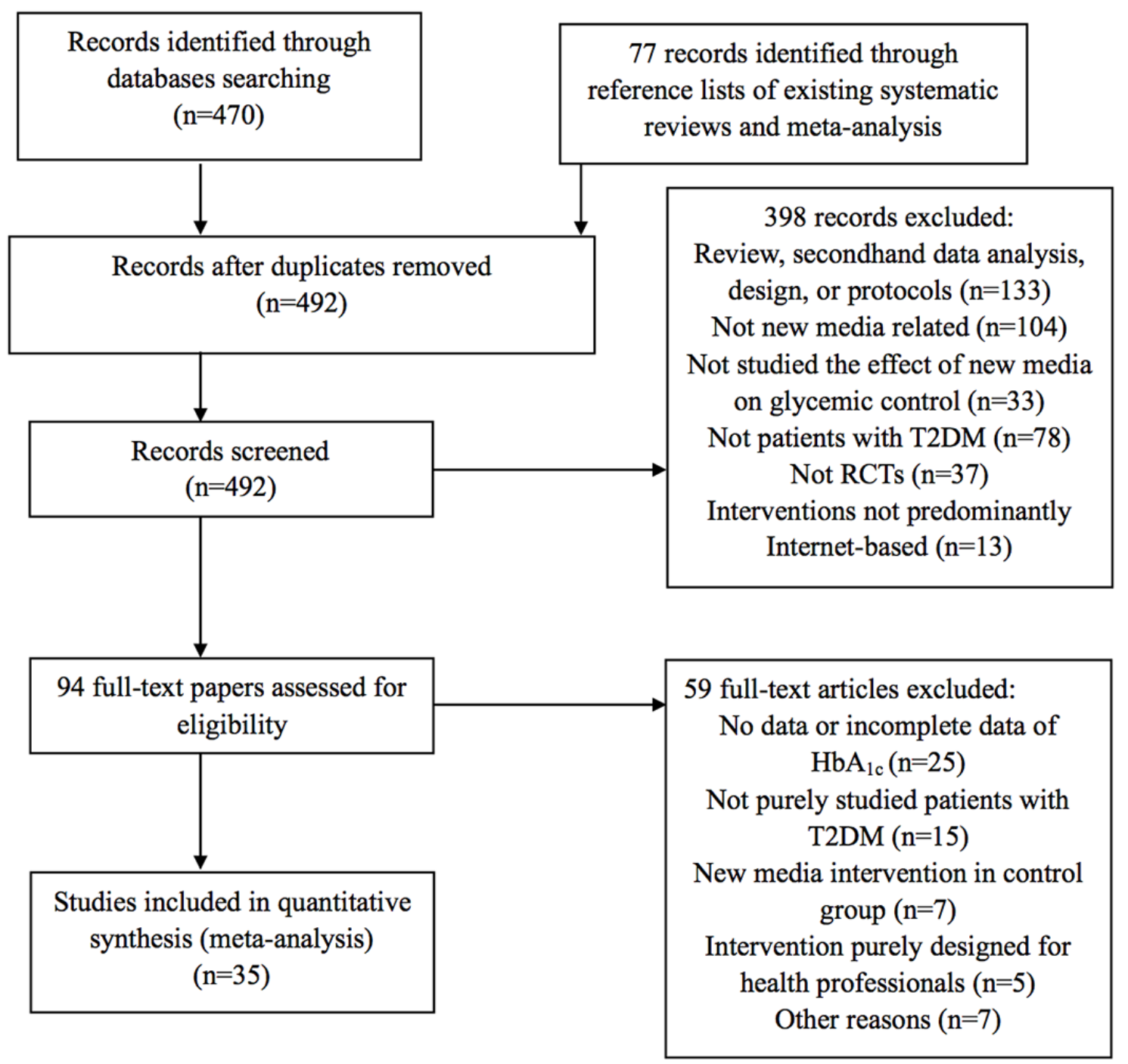


Mean values and $\mathrm{SD}$ of $\mathrm{HbA}_{1 \mathrm{c}}$ at baseline and endpoint were extracted separately for IGs and CGs. Some studies only presented changes of $\mathrm{HbA}_{1 \mathrm{c}}$, and in this case, $\mathrm{HbA}_{1 \mathrm{c}}$ values at endpoint were calculated correspondingly based on baseline and changes of values [8,16,25-27]. For studies that provided SE rather than SD, SD value was calculated based on the SE value [12,28-30]. Some studies gave $95 \% \mathrm{CI}$ of mean $\mathrm{HbA}_{1 \mathrm{c}}$, and SD was derived according to $95 \%$ CI $[14,25,31]$. If neither endpoint SD nor other information that could be used to calculate SD was provided, baseline SD was adopted as endpoint SD [26,32].

Cochrane collaboration's tool for assessing the risk of bias was adopted to evaluate the quality of studies included. Six domains were assessed, including selection bias, performance bias, detection bias, attrition bias, reporting bias, and other bias.

\section{Data Synthesis and Analysis}

Interstudy heterogeneity was evaluated by the $I^{2}$ test. If $I^{2} \leq 50 \%$, heterogeneity across studies was acceptable, and fixed effect model could be used to achieve the pooled result. If $I^{2}>50 \%$, random effect model would be used, and source of heterogeneity would be explored. Meta-analysis with continuous outcome variables was performed, and weighted mean difference (WMD) was adopted as the effect indicator. If $P<.05$ and $95 \%$ CI did not include zero, the point estimate of WMD was considered statistically significant. Publication bias was explored by Begg and Egger tests. Duval and Tweedie's nonparametric "trim-and-fill" procedure was also performed to further assess the possible effect of publication bias [33,34]. Sensitivity analysis was conducted to assess the stability of studies. Statistical analyses were performed with STATA/SE 14.1 (StataCorp LP, College Station, Texas) and risk of bias was evaluated with Review Manager (RevMan 5.3; Cochrane Collaboration).

\section{Results}

\section{Characteristics of Studies}

This meta-analysis included 35 studies with a pooled dataset of 6475 participants, of which 3338 were allocated to the IG and 3137 to CG [7-12,14,16,25-32,35-53]. The total number of patients in each study ranged from 30 to 1665 . The characteristics of eligible studies are presented in Multimedia Appendix 2.

Of the 35 studies included, 11 were conducted in the United States $[11,12,26,27,29,32,37,39,40,48,50] ; 10$ in the Republic of Korea [7,8,28,30,35,36,46,49,52,53]; 2 in Poland [38,45], Italy $[16,44]$, and China $[43,47]$ each; 1 in Japan [42], Finland [25], Turkey [10], Canada [9], Spain [31], Norway [14], England [41], and Congo[51] each. Included studies were published between 2004 and 2016, and the intervention duration ranged from 6 weeks to 5 years. The mean age of the participants ranged from 42.3 to 79.9 years and BMI from 22.8 to 36.9. All studies, except 2, clearly stated that all participants had T2DM. However, in these 2 studies, the mean age of the patients was above 60 years; therefore, it was assumed that the included participants were all patients with T2DM [29,50].

\section{Characteristics of Interventions}

A total of 8 studies used Web-based interventions solely $[7,9,10,12,28,38,43], \quad 8$ used mobile technology $[14,25,31,36,42,45,48,52]$, and 9 used a combination of both $[8,35,39,40,46,47,49,51,53]$. In addition, 10 studies used other forms of internet-based interventions, including portable digital assistant, tablet computer, and data transmission equipment only $[11,16,26,27,29,30,32,37,41,44]$. Moreover, 28 studies clearly stated ways of providing feedbacks, among which 5 used automated algorithm [25,36,39,46,52] and 22 provided feedbacks manually via health care providers [7,9-11,14,27-32, $35,37,40,41,43,44,48-51,53]$. In the automated algorithm, patient-specific messages were automatically generated and sent to patients based on the data entered into the system. Manual feedback was accomplished through telephone, videoconferencing, and short message services by cellular phone and the internet. A total of 14 studies provided internet-based education [8,10,27,29,32,37,39-41,43,47,49,50,53], and only 3 studies did not incorporate transmission function of glucose measurements $[8,12,47]$. A detailed description of intervention characteristics is presented in Multimedia Appendix 3.

Publication bias was detected by Egger test but not by Begg test. Trim-and-fill method was further conducted to account for publication bias. In trim-and-fill method, although the strength of intervention was slightly attenuated, the pooled analysis incorporating the hypothetical studies continued to show a statistically significant positive effect of internet-based interventions (WMD $-0.332,95 \% \mathrm{CI}-0.456$ to -0.209 ; $P<.001$; Multimedia Appendix 4), which suggested that the mean difference of $\mathrm{HbA}_{1 \mathrm{c}}$ between IG and CG was not an artifact of unpublished negative studies, but the effect of internet-based interventions. However, the possibility was not altogether excluded by this method. Detailed results on risk of bias, publication bias, and sensitivity analysis can be found in Multimedia Appendices 4-6. Multimedia Appendix 7 describes the $\mathrm{HbA}_{1 \mathrm{c}}$ value and related data of IG and CG at baseline and endpoint.

\section{Overall Results of Internet-Based Intervention}

All 35 studies provided mean values and SDs of $\mathrm{HbA}_{1 \mathrm{c}}$ as the outcome measure of internet-based interventions. At baseline, there was no significant difference of $\mathrm{HbA}_{1 \mathrm{c}}$ levels between the $\mathrm{CG}$ and IG as $95 \% \mathrm{CI}$ including zero (Figure 2).

Measurements made immediately after interventions were used to achieve the overall pooled effect of the internet-based intervention. In one study, 2 IGs met eligibility criteria, and therefore, information was extracted twice and treated as from 2 distinct studies [39]. They were marked as Quinn, C.C., 2011a and Quinn, C.C., 2011b in the analysis. Figure 3 presented the combined results of the 35 studies in this meta-analysis. The result showed that the WMD between CG and IG was -0.426 (95\% CI -0.540 to $-0.312 ; \quad P<.001$ ), favoring the IG. Heterogeneity was $60.1 \%$ across studies, and random effect model was adopted. 
Figure 2. Forest plots of baseline results. WMD: weighted mean difference.

Study

ID

WMD $(95 \% \mathrm{Cl}) \quad$ Weight

Zhou, P., 2014

Orsama, A. L., 2013

Avdal, E. U., 2011

Noh, J. H., 2010

Tildesley, H. D., 2010

Cho, J. H., 2006

Kwon, H. S., 2004

Rodriguez-Idigoras, M. I., 2009

Lim, S., 2016

Forjuoh, S. N., 2014

Glasgow, R. E., 2010

Quinn, C. C., 2011 a

Quinn, C. C., 2011 b

Bujnowska-Fedak, 2011

Hsu, W. C., 2016

Dario, C., 2016

Torbjornsen, A., 2014

Kardas, P., 2016

Nicolucci, A., 2015

Tang, P. C., 2013

Kim, H. S., 2007a

Kim, C. S., 2010

Wakefield, B. J., 2014

Stone, R. A., 2010

Pressman, A. R., 2014

Steventon, A., 2014

Kayo Waki, MD, 2014

Greenwood, D. A., 2015

Weinstock, R. S., 2011

Liu,C.T.

Kim, H.S.

Faridi, Z

McMahon, G.T.

Takenga, C

Yoo, H.J.

Yoon, K.H.

Overall (I-squared $=0.0 \%, p=0.907$ )

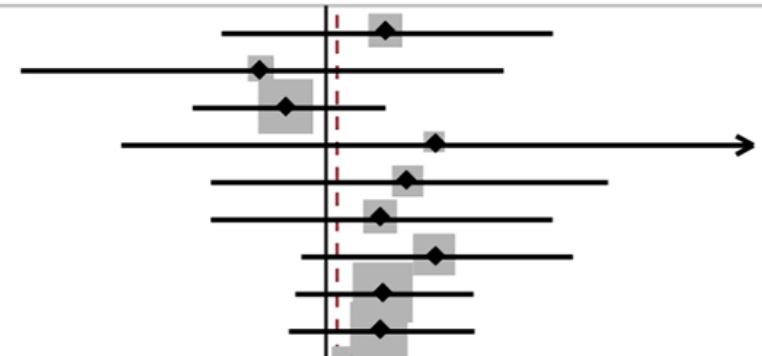

$0.22(-0.38,0.82) \quad 1.18$

$-0.23(-1.10,0.64) \quad 0.56$

$-0.13(-0.48,0.21) \quad 3.47$

$0.40(-0.74,1.54) \quad 0.32$

$0.30(-0.41,1.01) \quad 0.82$

$0.20(-0.42,0.82) \quad 1.11$

$0.40(-0.09,0.89) \quad 1.76$

$0.21(-0.11,0.53) \quad 4.09$

$0.20(-0.13,0.53) \quad 3.77$

$0.10(-0.37,0.57) \quad 1.87$

$-0.05(-0.46,0.36) \quad 2.50$

$-0.20(-1.07,0.67) \quad 0.55$

$0.70(0.01,1.39) \quad 0.89$

$0.02(-0.62,0.66) \quad 1.03$

$-0.10(-0.84,0.64) \quad 0.76$

$0.01(-0.25,0.27) \quad 6.10$

$-0.20(-0.65,0.25) \quad 2.08$

$-0.06(-0.59,0.47) \quad 1.49$

$-0.10(-0.27,0.07) \quad 14.58$

$-0.04(-0.36,0.28) \quad 4.09$

$0.50(-0.29,1.29) \quad 0.67$

$0.00(-0.51,0.51) \quad 1.61$

$-0.20(-0.74,0.34) \quad 1.43$

$0.20(-0.31,0.71) \quad 1.64$

$0.20(-0.25,0.65) \quad 2.11$

$-0.03(-0.34,0.28) \quad 4.43$

$0.10(-0.41,0.61) \quad 1.63$

$0.30(-0.15,0.75) \quad 2.03$

$-0.02(-0.17,0.13) \quad 17.94$

$0.08(-0.52,0.68) \quad 1.18$

$0.50(-0.22,1.22) \quad 0.80$

$-0.10(-0.57,0.37) \quad 1.93$

$0.10(-0.21,0.41) \quad 4.44$

$0.08(-0.67,0.83) \quad 0.74$

$0.20(-0.13,0.53) \quad 3.74$

$0.50(-0.29,1.29) \quad 0.67$

$0.04(-0.02,0.10) \quad 100.00$

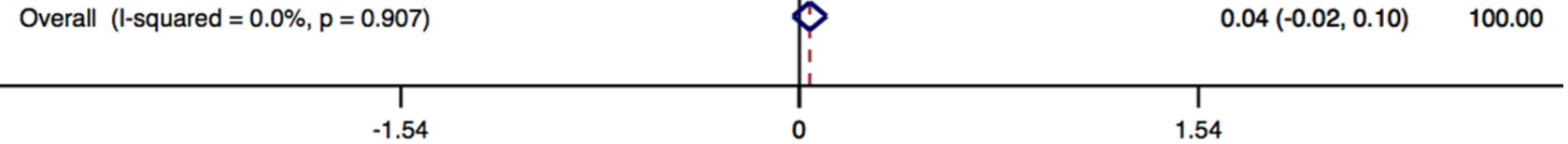


Figure 3. Forest plots of endpoint results. WMD: weighted mean difference.

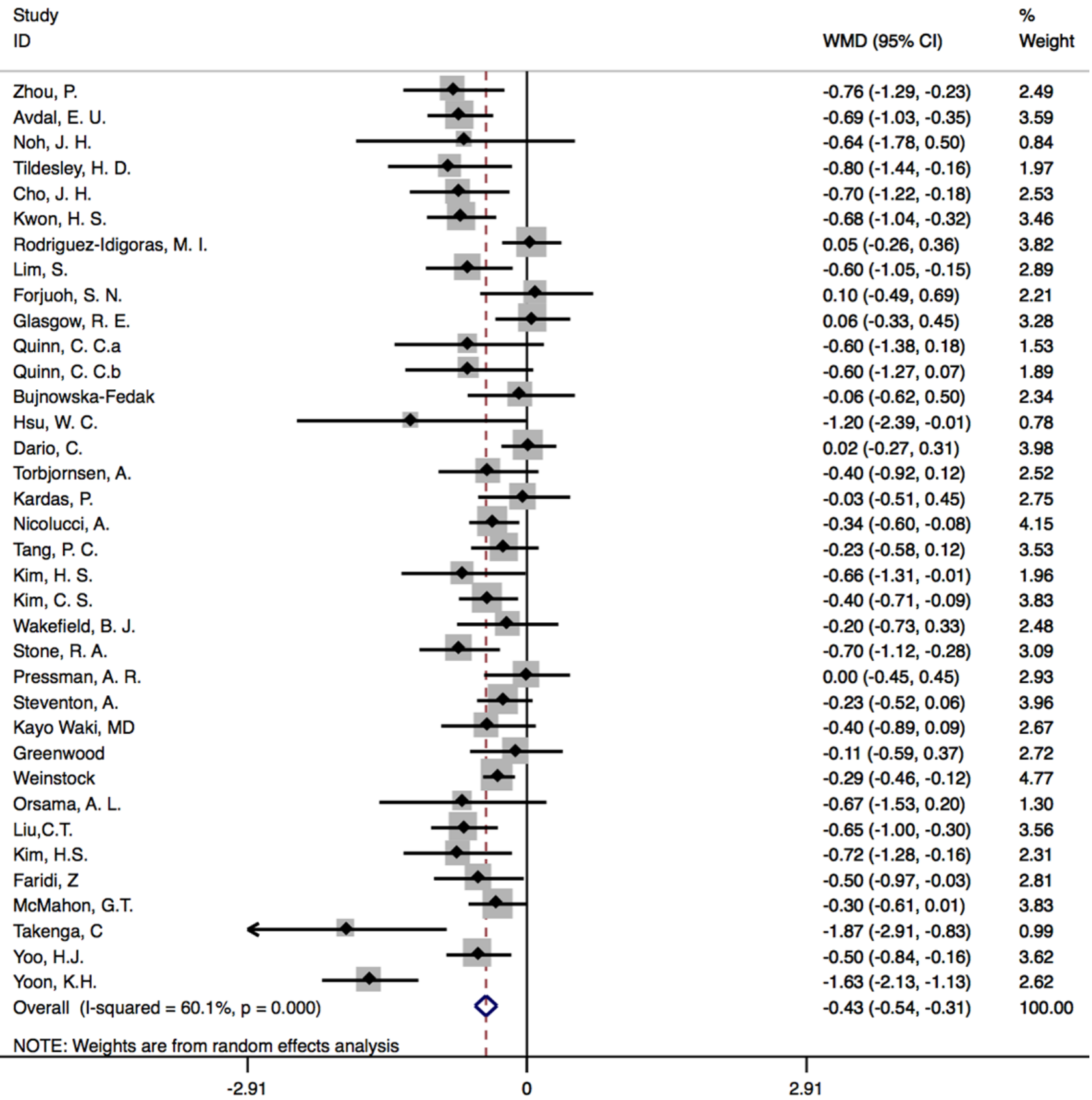

\section{Subgroup Analysis}

Subgroup analyses were conducted based on intervention duration, types of internet-based interventions, ways of feedback provision, and whether or not internet-based educational content was provided.

\section{Results of Subgroup Analysis Based on Intervention Duration}

As intervention duration in the 35 studies ranged from 12 weeks to 5 years, we divided included research into 3 mutually exclusive groups ( $x \leq 3$ months: $n=10,3$ months $<x \leq 6$ months: $\mathrm{n}=10$, and $\mathrm{x}>6$ months: $\mathrm{n}=16$ ) to perform subgroup analysis. In the group of $x \leq 3$ months $[11,28,30,36,42,43,45,48,51,52]$, heterogeneity across studies was $41.8 \%$ and the pooled WMD was $-0.51 \%$ (95\% CI -0.71 to $-0.31 ; P<.001)$. Significant difference between IG and CG was also observed in the group of duration $>3$ months and $\leq 6$ months [8-10,27,32,35,37,38,46,49], with a pooled WMD of $-0.48 \%$ (95\% CI -0.68 to $-0.28 ; P<.001$ ). The heterogeneity across study was $34.5 \%$. In the group of duration $>6$ months $[7,12,14,16,25,26,29,31,39-41,44,47,50,53]$, difference in $\mathrm{HbA}_{1 \mathrm{c}}$ outcomes between IG and CG groups decreased with a WMD of $-0.35 \%(95 \% \mathrm{CI}-0.53$ to $-0.18 ; P<.001)$ and heterogeneity increased to $70.5 \%$ (Figure 4 ). 
Figure 4. Subgroup analysis based on intervention duration. WMD: weighted mean difference.

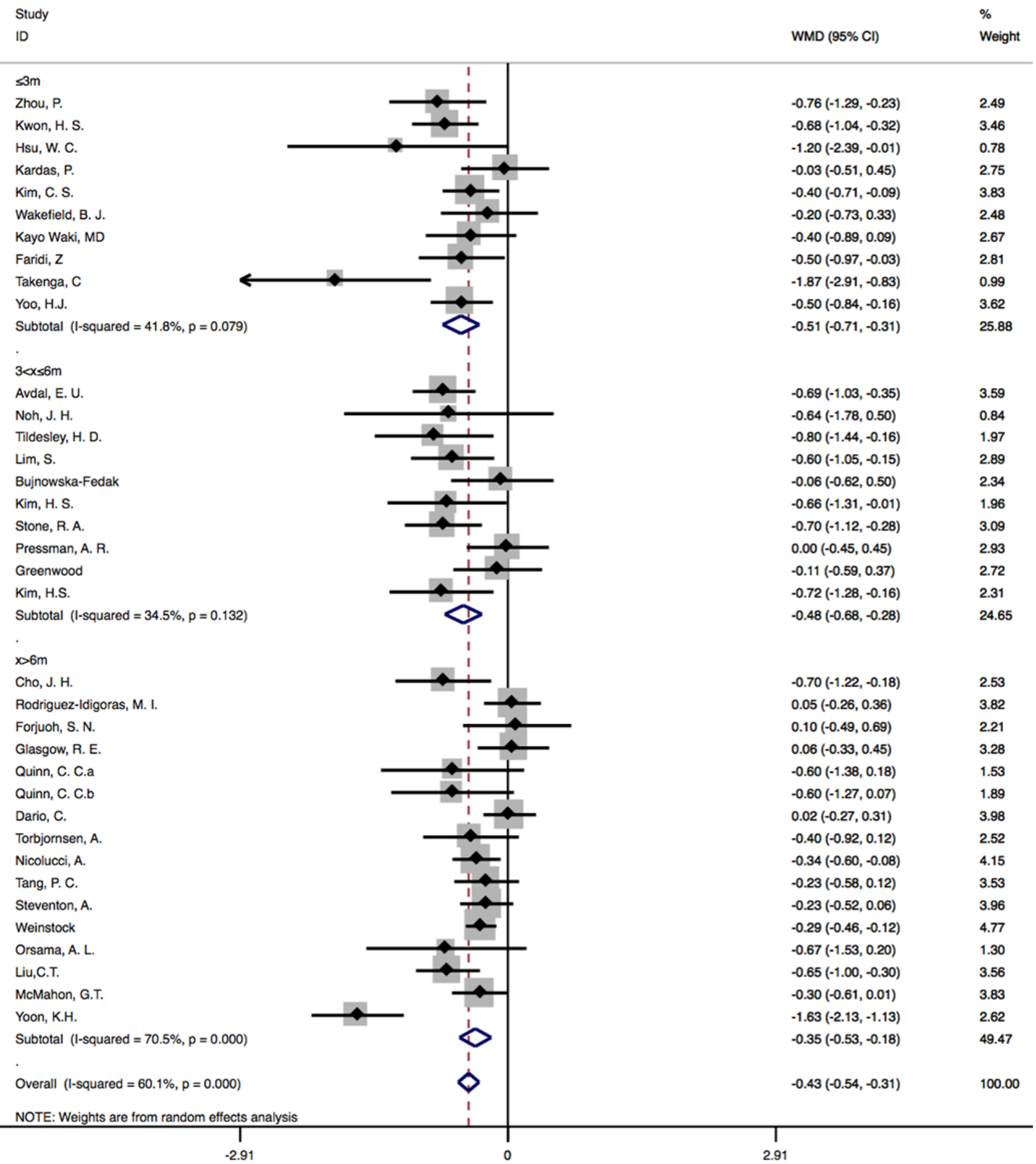

\section{Results of Subgroup Analysis Based on the Type of Internet-Based interventions}

In this analysis, we divided 35 studies into 4 subgroups based on types of internet-based interventions (Web-based solely: $\mathrm{n}=8$, mobile-based solely: $\mathrm{n}=8$, combined website and mobile technology: $n=10$, and others: $n=10$ ). Forms of intervention that did not fall in the above 3 categories were classified as others. In the group of website-only interventions $[7,9,10,12,28,38,43,50]$, there was statistically significant difference in $\mathrm{HbA}_{1 \mathrm{c}}$ outcomes between IG and CG, and WMD was $-0.48 \%$ ( $95 \% \mathrm{CI}-0.71$ to $-0.24 ; P<.001)$. However, a moderate heterogeneity of $57 \%$ was also observed across studies in this subgroup. In the group of mobile-only interventions [14,25,31,36,42,45,48,52], difference in $\mathrm{HbA}_{1 \mathrm{c}}$ between IG and CG decreased, with a pooled WMD of $-0.31 \%(95 \% \mathrm{CI}-0.49$ to $-0.14 ; P<.001)$ and heterogeneity of $27.2 \%$. In combined mobile and website group [8,35,39,40,46,47,49,51,53], a heterogeneity of $64.6 \%$ was observed, and the pooled effect was $-0.77 \%$ (95\% CI -1.07 to $-0.47 ; P<.001)$. In the group of other intervention types, heterogeneity across studies was $35.5 \%$, with a pooled WMD of $-0.23(95 \% \mathrm{CI}-0.38$ to $-0.09 ; P=.001$; Figure 5). 
Figure 5. Subgroup analysis based on the type of internet-based interventions. WMD: weighted mean difference.

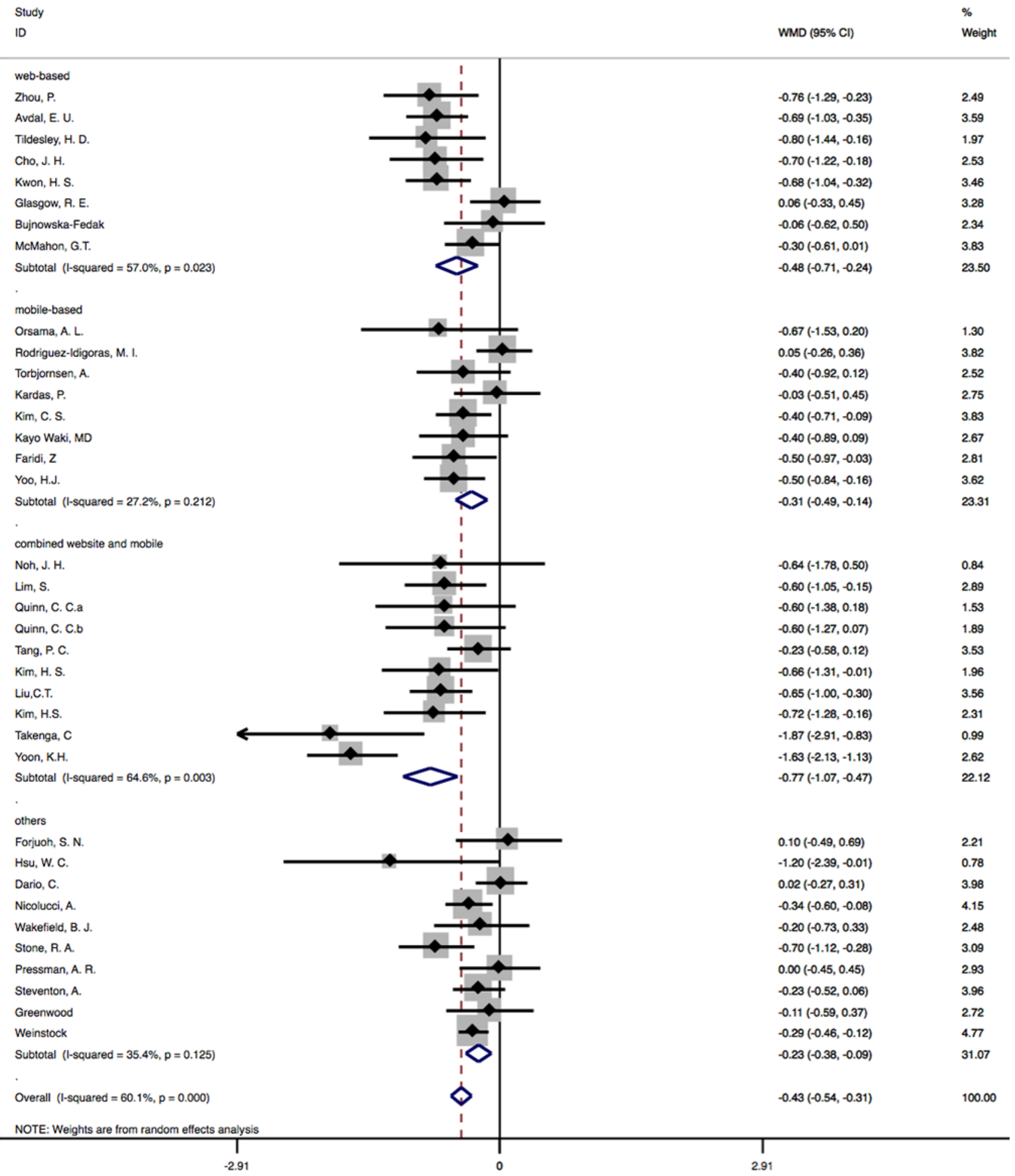

\section{Results of Subgroup Analysis Based on Feedback Provision}

We divided included studies into 3 groups (manual: $n=22$, automated: $n=6$, and unclear: $n=8$ ) to perform subgroup analysis based on feedback provision. A total of 8 studies did not specifically mention ways of providing feedback and thus were classified as unclear. In the group of manual feedback [7,9-11,14,27-32,35,37,40,41,43,44,48-51,53], statistically significant difference in $\mathrm{HbA}_{1 \mathrm{c}}$ between $\mathrm{CG}$ and IG was observed, and heterogeneity across studies was 67.2\% (WMD $-0.50 \%, 95 \%$ CI -0.65 to $-0.34 ; P<.001)$. In studies that provided automated feedbacks $[25,36,39,46,52]$, heterogeneity was reduced to $0.0 \%$, and difference between groups was $-0.50 \%$ (95\% CI -0.69 to $-0.32 ; P<.001)$. In unclear group $[8,12,16,26,38,42,45,47]$, difference in $\mathrm{HbA}_{1 \mathrm{c}}$ outcomes was not significant as $P=.14$, which is greater than .05 (WMD $-0.17 \%, 95 \% \mathrm{CI}-0.39$ to -0.06$)$, and heterogeneity across studies was $46.9 \%$ (Figure 6). 
Figure 6. Subgroup analysis based on feedback provision. WMD: weighted mean difference.

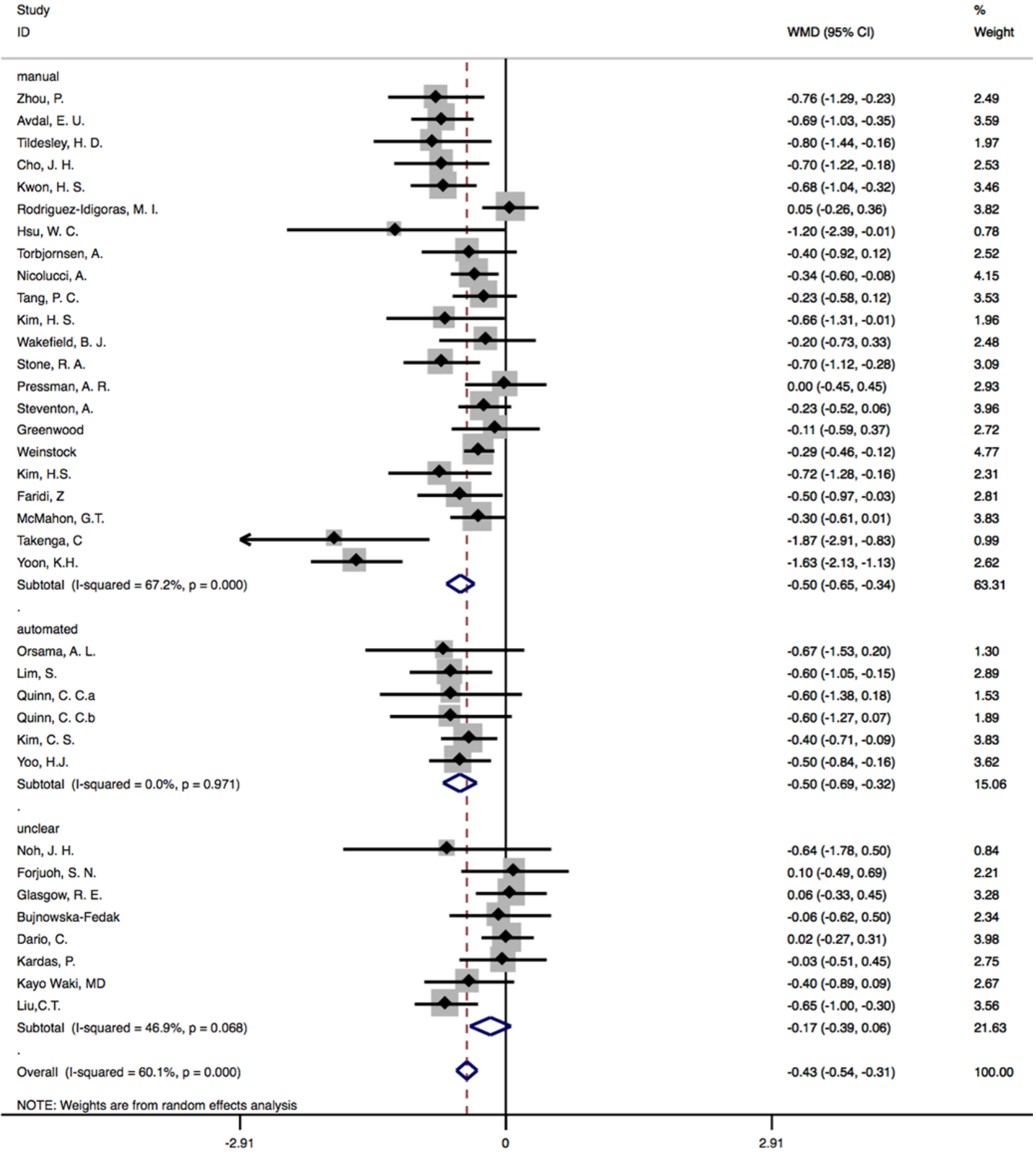

\section{Results of Subgroup Analysis Based on Internet-Based Education Provision}

On the basis of internet-based education provision, 35 studies were divided into 2 subgroups (yes: $n=15$; no: $n=21$ ). In the group that provided internet-based diabetes education $[8,10,27,29,32,37,39-41,43,47,49,50,53]$, there was significant difference between CG and IG, with a pooled WMD of $-0.51 \%$ (95\% CI -0.69 to $-0.32 ; P<.001$ ), and heterogeneity across studies was $66.9 \%$. In the group without internet-based

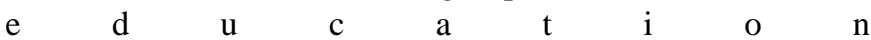
[7,9,11,12,14,16,25,26,28,30,31,35,36,38,42,44-46,48,51,52], heterogeneity decreased to $53.6 \%$, and WMD was $-0.36 \%(95 \%$ CI -0.51 to $-0.22 ; P<.001$; Figure 7 ). 
Figure 7. Subgroup analysis based on internet-based education provision. WMD: weighted mean difference.

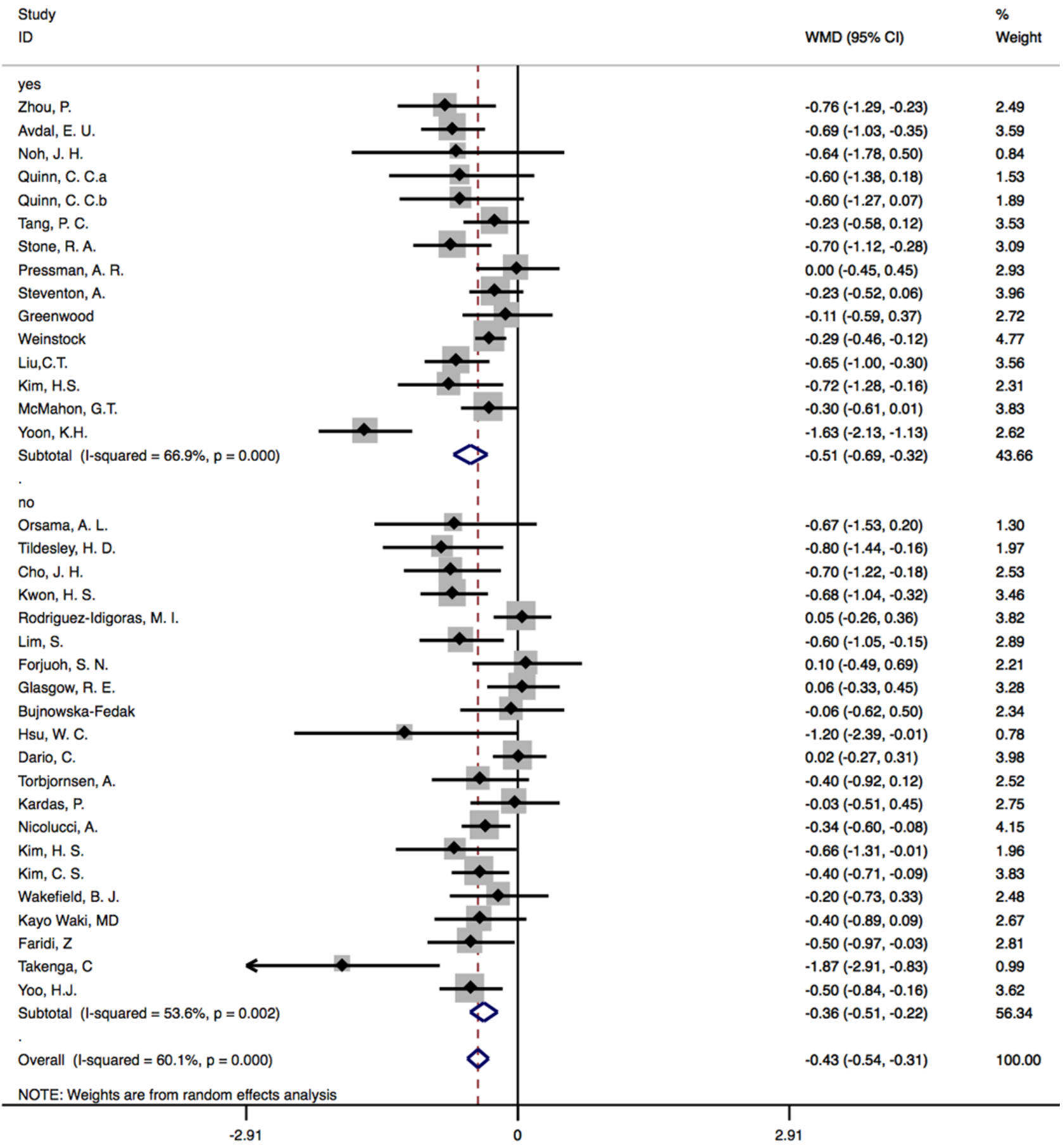

\section{Discussion}

\section{Principal Findings}

This meta-analysis included $35 \mathrm{RCT}$ studies to evaluate the effect of internet-based interventions on patients with T2DM. WMD of $\mathrm{HbA}_{1 \mathrm{c}}$ value was adopted as the effect indicator of glucose control, and results indicated that the mean difference of $\mathrm{HbA}_{1 \mathrm{c}}$ values between the $\mathrm{CG}$ and internet-based interventions was $0.43 \%$, favoring the internet-based interventions. It is reported in research that each $1 \%$ decrease of mean $\mathrm{HbA}_{1 \mathrm{c}}$ values will lead to $21 \%$ reduction of risk for any endpoint related to diabetes, including death, myocardial

infarction, and microvascular complications [54]. Therefore, optimizing the utilization of internet-based interventions in the management of T2DM has great importance.

\section{Intervention Duration}

Duration has a significant influence on the effect of internet-based interventions. Results of this meta-analysis indicate a downward trend of intervention effect with an increasing duration, which is similar to that in other systematic reviews and meta-analyses [19,23]. There are some possible rationales that may serve to explain such differences over time. First, the decline of efficacy may be attributed to patients' diminishing enthusiasm or motivation with the passage of intervention, especially when most of the studies included in 
this meta-analysis involve a regular or daily transmission of glucose data. Second, a lack of user-friendliness could also result in attenuated effect. As the mean age of recruited participants exceeds 40 years, new forms of technology may not be familiar and friendly for them. However, this result does not encourage the shortening of intervention periods, but rather it indicates that relative measures should be taken to increase patients' adherence and maintain their motivation, with the aim to prevent attenuated intervention effect over time. Furthermore, it is promising to develop a form of internet-based intervention that is both effective and friendly to use.

\section{Types of Internet-Based Interventions}

In terms of the types of internet-based interventions, there is not a consensus in previous meta-analyses on which form is the most effective. In this paper, combined website and mobile interventions have the largest WMD of $\mathrm{HbA}_{1 \mathrm{c}}$, followed by Web-based only interventions. Mobile-based only interventions have the lowest mean difference, which indicates that mobile technologies may not be the optimal options in diabetes management. This result coincides with some findings in Toma's meta-analysis [23]. Toma discovered that the effect of mobile-only interventions in $\mathrm{HbA}_{1 \mathrm{c}}$ outcomes was the poorest and not statistically important (WMD $-0.20 \%, 95 \%$ CI -0.43 to $0.03 ; P=.09$ ), whereas combined mobile and websites interventions yielded the best performance (WMD $-0.54 \%$, $95 \%$ CI -0.72 to $-0.37 ; P<.001)$. Results of websites-only interventions were similar to those in this meta-analysis (WMD $-0.51 \%, 95 \%$ CI -0.68 to -0.34 ). However, in another 2 meta-analyses exploring the effect of mobile-based interventions on diabetes management, the WMD in $\mathrm{HbA}_{1 \mathrm{c}}$ outcomes was $-0.40 \%(95 \% \mathrm{CI}-0.69$ to $-0.11 ; P=.007)$ and $-0.50 \%(95 \% \mathrm{CI}$ -0.7 to -0.3 ) [22,55]. A possible explanation may be that in most studies included ( 7 out of 8 ) in this meta-analysis, a new mobile phone with functions related to diabetes management is provided to participants to replace their own cellular phones, rather than installing a diabetic application in their old ones $[14,25,31,42,45,48,52]$. Therefore, it is likely that such diabetic phones are not user-friendly and require some time to get familiar with. As a result, patients' satisfaction toward study and frequency of data transmission may be compromised, which further leads to the compromise of $\mathrm{HbA}_{1 \mathrm{c}}$ performance ultimately. Furthermore, the fact that Pal's meta-analysis on mobile interventions only included 3 studies and Cui's meta-analysis also involved some studies that combined the use of mobile phone and websites may also contribute to the contradictory situation [22,55]. However, this result does not imply that we should altogether abandon mobile-based interventions, as it is drawn from the currently available evidence and therefore may lag in time. Due to the high penetration and convenience offered by mobile phones, they have great potentials in diabetes management, and future studies need to explore the effectiveness of apps that are easy to use and directly installed on patients' own cellular phones.

\section{Forms of Feedback Provision and Function of Internet-Based Educational Contents}

Automated feedbacks generated by algorithms yield similar effect to feedbacks provided manually. As automated algorithms could save manual labor and also provide real-time feedback as soon as patients enter data, it may have great potentials to alleviate the social and economic burden brought by various chronic diseases.

Furthermore, although various clinical guidelines have acknowledged the importance and effectiveness of diabetes education, only $40 \%$ of studies included in this meta-analysis embody this feature $[4,5]$. This result coincides with a previous review where among mobile diabetes apps on the market, only $20 \%$ of them had an educational module [3].

\section{Limitations of This Meta-Analysis}

This meta-analysis also has some limitations. First of all, because of limited time, we only searched 3 databases. Although we tried to identify studies from the reference lists of other reviews and include those published in other languages, it is possible that some studies in other databases and gray literature are overlooked. Second, although the studies included in this meta-analysis are all RCTs and the quality of evidence is relatively higher, only a few reported blinding of the outcome assessment process. Therefore, it is possible that performance bias is introduced. Third, in some studies, CGs also use some forms of intervention rather than purely usual care, such as paper-based education, note-keeping of glucose levels, and telephone follow-ups. Furthermore, contents of usual care in different locations may also vary. Therefore, this could also bias the genuine effects of internet-based interventions. Fourth, in some subgroup analyses, results are drawn from a small number of studies and heterogeneity is high. Finally, although the trim-and-fill method did not change the general effect of internet-based interventions, suggesting that the effect was not an artifact of unpublished negative studies, the possibility was not fully ruled out.

\section{Implications for Future Studies and Clinical Practices}

First of all, although blinding of participants and health care providers seems impossible because of the nature of the intervention, only a few studies explicitly reported that the outcome assessment process was blinded. In future studies, more importance should be attached to the blinding of outcome assessment because this is a process that should be achieved regardless of the type interventions. Only in this way, could performance bias be reduced to a minimum and a reliable effect be revealed.

Second, subgroup analysis indicates that automated feedback provision has a similar effect to manual feedback provision; therefore, it is promising to take full advantage of automated algorithms, as it could not only provide real-time feedbacks but also save manual labors. However, the number of studies in this aspect is limited and few have explored its cost-effectiveness and patients' satisfaction. As a result, future studies need not only examine the efficacy of automated feedback provision but also evaluate the feasibility of promotion on a large scale.

Third, future studies need to integrate diabetes-related functions to existing technologies, such as developing diabetic apps, which could be directly installed into patients' own mobile phones, rather than developing new types of phones. Only in this way, the true effect of mobile interventions can be revealed. 
Finally, results in this meta-analysis also shed some light on clinical practices. If health care practitioners would like to use the internet as a way to help patients manage their glycemic levels, a combined use of websites and mobile technologies may achieve a better outcome than a standalone method. Furthermore, if there are currently available mobile apps on the market, practitioners may as well recommend patients to download such apps into their own mobile phones, rather than developing a new one for them. Moreover, as internet-based health education for diabetes management is proven to be effective, if due to various reasons health care providers could not provide a systematic and comprehensive intervention for patients, they could recommend some reliable and informative websites or information resources with diabetes-related contents that could be easily understood by patients.

\section{Conclusions}

In conclusion, the WMD of endpoint $\mathrm{HbA}_{1 \mathrm{c}}$ between internet-based interventions and usual care was $-0.426 \%$. Optimal outcomes appear in intervention duration of $\leq 3$ months. In terms of the types of internet-based interventions, according to currently available evidence, combined interventions of websites and mobile technologies yield better results, and more studies are needed to explore the potentials of mobile technologies. Results also indicate that automated feedback has similar effects to feedbacks provided manually, and interventions with internet-based educational contents have better performance. As a result, interventions integrating the above elements may achieve more satisfactory results and help patients manage their glycemic levels effectively.

\section{Acknowledgments}

The authors would like to thank Daniel Dvuillermin, Lang Lang, Xuxi Zhang and Jian Zhang for their help in improving the language of this paper and providing helpful suggestions on the paper. This study was supported by the National Natural Science Foundation of China (Grant No. 71673009).

\section{Authors' Contributions}

XYS and YS provided the original idea for the meta-analysis. YS and FBW were responsible for the study design, study selection, and data extraction, with input from XYS, QDS, and XZ. YS, XZ, and XRZ performed statistical analysis. QDS contributed greatly to manuscript revision. XRZ, XYS, QDS, and EBF accomplished result interpretation. All authors wrote the manuscript and revised the paper for important intellectual content. All authors approved this manuscript.

\section{Conflicts of Interest}

None declared.

\section{Multimedia Appendix 1}

Details of search syntax.

[PDF File (Adobe PDF File), 122KB-Multimedia Appendix 1]

\section{Multimedia Appendix 2}

Characteristics of eligible studies included in meta-analysis.

[PDF File (Adobe PDF File), 182KB-Multimedia Appendix 2]

\section{Multimedia Appendix 3}

Characteristics of intervention group (IG) and control group (CG).

[PDF File (Adobe PDF File), 67KB-Multimedia Appendix 3]

\section{Multimedia Appendix 4}

Publication bias.

[PDF File (Adobe PDF File), 363KB-Multimedia Appendix 4]

\section{Multimedia Appendix 5}

Risk of bias. 


\section{Multimedia Appendix 6}

Sensitivity analysis.

[PDF File (Adobe PDF File), 88KB-Multimedia Appendix 6]

\section{Multimedia Appendix 7}

$\mathrm{HbA}_{1 \mathrm{c}}$ value and related data of intervention group (IG) and control group (CG) at baseline and different intervention periods.

[PDF File (Adobe PDF File), 55KB-Multimedia Appendix 7]

\section{References}

1. Singh G, O'Donoghue J, Soon CK. Telemedicine: issues and implications. Technol Health Care 2002;10(1):1-10. [Medline: 11847443 ]

2. Smith JC, Schatz BR. Feasibility of mobile phone-based management of chronic illness. AMIA Annu Symp Proc 2010 Nov 13;2010:757-761 [FREE Full text] [Medline: 21347080]

3. Chomutare T, Fernandez-Luque L, Arsand E, Hartvigsen G. Features of mobile diabetes applications: review of the literature and analysis of current applications compared against evidence-based guidelines. J Med Internet Res 2011;13(3):e65 [FREE Full text] [doi: 10.2196/jmir.1874] [Medline: 21979293]

4. Sibal L, Home PD. Management of type 2 diabetes: NICE guidelines. Clin Med (Lond) 2009 Aug;9(4):353-357. [Medline: $\underline{19728510]}$

5. Funnell MM. Standards of care for diabetes: what's new? Nursing 2010 Oct;40(10):54-56. [doi: 10.1097/01.NURSE.0000388314.83393.bd] [Medline: 20844399]

6. Ramadas A, Quek KF, Chan CK, Oldenburg B. Web-based interventions for the management of type 2 diabetes mellitus: a systematic review of recent evidence. Int J Med Inform 2011 Jun;80(6):389-405. [doi: 10.1016/j.ijmedinf.2011.02.002] [Medline: 21481632]

7. Cho JH, Chang SA, Kwon HS, Choi YH, Ko SH, Moon SD, et al. Long-term effect of the Internet-based glucose monitoring system on HbA1c reduction and glucose stability: a 30-month follow-up study for diabetes management with a ubiquitous medical care system. Diabetes Care 2006 Dec;29(12):2625-2631. [doi: 10.2337/dc05-2371] [Medline: 17130195]

8. Noh JH, Cho YJ, Nam HW, Kim JH, Kim DJ, Yoo HS, et al. Web-based comprehensive information system for self-management of diabetes mellitus. Diabetes Technol Ther 2010 May;12(5):333-337. [doi: 10.1089/dia.2009.0122] [Medline: 20388042]

9. Tildesley HD, Mazanderani AB, Ross SA. Effect of Internet therapeutic intervention on A1C levels in patients with type 2 diabetes treated with insulin. Diabetes Care 2010 Aug;33(8):1738-1740 [FREE Full text] [doi: 10.2337/dc09-2256] [Medline: 20668152]

10. Avdal EU, Kizilci S, Demirel N. The effects of web-based diabetes education on diabetes care results: a randomized control study. Comput Inform Nurs 2011 Feb;29(2):101-106. [doi: 10.1097/NCN.0b013e3181fcbdc6] [Medline: 21099675]

11. Hsu WC, Lau KH, Huang R, Ghiloni S, Le H, Gilroy S, et al. Utilization of a cloud-based diabetes management program for insulin initiation and titration enables collaborative decision making between healthcare providers and patients. Diabetes Technol Ther 2016 Feb;18(2):59-67 [FREE Full text] [doi: 10.1089/dia.2015.0160] [Medline: 26645932]

12. Glasgow RE, Kurz D, King D, Dickman JM, Faber AJ, Halterman E, et al. Outcomes of minimal and moderate support versions of an internet-based diabetes self-management support program. J Gen Intern Med 2010 Dec;25(12):1315-1322 [FREE Full text] [doi: 10.1007/s11606-010-1480-0] [Medline: 20714820]

13. Holmen H, Torbjørnsen A, Wahl AK, Jenum AK, Småstuen MC, Arsand E, et al. A mobile health intervention for self-management and lifestyle change for persons with type 2 diabetes, part 2: one-year results from the Norwegian randomized controlled trial RENEWING HEALTH. JMIR Mhealth Uhealth 2014;2(4):e57 [FREE Full text] [doi: 10.2196/mhealth.3882] [Medline: 25499872]

14. Torbjørnsen A, Jenum AK, Småstuen MC, Arsand E, Holmen H, Wahl AK, et al. A low-intensity mobile health intervention with and without health counseling for persons with type 2 diabetes, part 1: baseline and short-term results from a randomized controlled trial in the Norwegian part of RENEWING HEALTH. JMIR Mhealth Uhealth 2014;2(4):e52 [FREE Full text] [doi: 10.2196/mhealth.3535] [Medline: 25499592]

15. Karhula T, Vuorinen A, Rääpysjärvi K, Pakanen M, Itkonen P, Tepponen M, et al. Telemonitoring and mobile phone-based health coaching among Finnish diabetic and heart disease patients: randomized controlled trial. J Med Internet Res 2015;17(6):e153 [FREE Full text] [doi: 10.2196/jmir.4059] [Medline: 26084979]

16. Dario C, Toffanin R, Calcaterra F, Saccavini C, Stafylas P, Mancin S, et al. Telemonitoring of type 2 diabetes mellitus in Italy. Telemed J E Health 2017;23:143-152. [doi: 10.1089/tmj.2015.0224] [Medline: 27379995]

17. Angeles RN, Howard MI, Dolovich L. The effectiveness of web-based tools for improving blood glucose control in patients with diabetes mellitus: a meta-analysis. Can J Diabetes 2011 Jan;35(4):344-352. [doi: 10.1016/S1499-2671(11)54011-0]

18. Azar M, Gabbay R. Web-based management of diabetes through glucose uploads: has the time come for telemedicine? Diabetes Res Clin Pract 2009 Jan;83(1):9-17. [doi: 10.1016/j.diabres.2008.09.055] [Medline: 19056140] 
19. Hou C, Carter B, Hewitt J, Francisa T, Mayor S. Do mobile phone applications improve glycemic control (HbA1c) in the self-management of diabetes? A systematic review, meta-analysis, and grade of 14 randomized trials. Diabetes Care 2016 Dec;39(11):2089-2095. [doi: 10.2337/dc16-0346] [Medline: 27926892]

20. Mushcab H, Kernohan WG, Wallace J, Martin S. Web-based remote monitoring systems for self-managing type 2 diabetes: a systematic review. Diabetes Technol Ther 2015 Jul;17(7):498-509. [doi: 10.1089/dia.2014.0296] [Medline: 25830528]

21. Pereira K, Phillips B, Johnson C, Vorderstrasse A. Internet delivered diabetes self-management education: a review. Diabetes Technol Ther 2015 Jan;17(1):55-63. [doi: 10.1089/dia.2014.0155] [Medline: 25238257]

22. Cui M, Wu X, Mao J, Wang X, Nie M. T2DM self-management via smartphone applications: a systematic review and meta-analysis. PLoS One 2016;11(11):e0166718 [FREE Full text] [doi: 10.1371/journal.pone.0166718] [Medline: 27861583]

23. Toma T, Athanasiou T, Harling L, Darzi A, Ashrafian H. Online social networking services in the management of patients with diabetes mellitus: systematic review and meta-analysis of randomised controlled trials. Diabetes Res Clin Pract 2014 Nov;106(2):200-211. [doi: 10.1016/j.diabres.2014.06.008] [Medline: 25043399]

24. Zhang X, Yang S, Sun K, Fisher EB, Sun X. How to achieve better effect of peer support among adults with type 2 diabetes: a meta-analysis of randomized clinical trials. Patient Educ Couns 2016 Feb;99(2):186-197. [doi: 10.1016/j.pec.2015.09.006] [Medline: 26463156]

25. Orsama A, Lähteenmäki J, Harno K, Kulju M, Wintergerst E, Schachner H, et al. Active assistance technology reduces glycosylated hemoglobin and weight in individuals with type 2 diabetes: results of a theory-based randomized trial. Diabetes Technol Ther 2013 Aug;15(8):662-669. [doi: 10.1089/dia.2013.0056] [Medline: 23844570]

26. Forjuoh SN, Bolin JN, Huber Jr JC, Vuong AM, Adepoju OE, Helduser JW, et al. Behavioral and technological interventions targeting glycemic control in a racially/ethnically diverse population: a randomized controlled trial. BMC Public Health 2014;14:71 [FREE Full text] [doi: 10.1186/1471-2458-14-71] [Medline: 24450992]

27. Pressman AR, Kinoshita L, Kirk S, Barbosa GM, Chou C, Minkoff J. A novel telemonitoring device for improving diabetes control: protocol and results from a randomized clinical trial. Telemed J E Health 2014 Feb;20(2):109-114. [doi:

10.1089/tmj.2013.0157] [Medline: 24404816]

28. Kwon HS, Cho JH, Kim HS, Song BR, Ko SH, Lee JM, et al. Establishment of blood glucose monitoring system using the internet. Diabetes Care 2004 Feb;27(2):478-483. [Medline: 14747232]

29. Weinstock RS, Teresi JA, Goland R, Izquierdo R, Palmas W, Eimicke JP, et al. Glycemic control and health disparities in older ethnically diverse underserved adults with diabetes: five-year results from the Informatics for Diabetes Education and Telemedicine (IDEATel) study. Diabetes Care 2011 Feb;34(2):274-279 [FREE Full text] [doi: 10.2337/dc10-1346] [Medline: 21270184]

30. Wakefield BJ, Koopman RJ, Keplinger LE, Bomar M, Bernt B, Johanning JL, et al. Effect of home telemonitoring on glycemic and blood pressure control in primary care clinic patients with diabetes. Telemed J E Health 2014 Mar;20(3):199-205 [FREE Full text] [doi: 10.1089/tmj.2013.0151] [Medline: 24404819]

31. Rodríguez-Idígoras MI, Sepúlveda-Muñoz J, Sánchez-Garrido-Escudero R, Martínez-González JL, Escolar-Castelló JL, Paniagua-Gómez IM, et al. Telemedicine influence on the follow-up of type 2 diabetes patients. Diabetes Technol Ther $2009 \mathrm{Jul} ; 11(7): 431-437$. [doi: 10.1089/dia.2008.0114] [Medline: 19580356]

32. Greenwood DA, Blozis SA, Young HM, Nesbitt TS, Quinn CC. Overcoming clinical inertia: a randomized clinical trial of a telehealth remote monitoring intervention using paired glucose testing in adults with type 2 diabetes. J Med Internet Res 2015;17(7):e178 [FREE Full text] [doi: 10.2196/jmir.4112] [Medline: 26199142]

33. Duval S, Tweedie R. Trim and fill: a simple funnel-plot-based method of testing and adjusting for publication bias in meta-analysis. Biometrics 2000 Jun;56(2):455-463. [Medline: 10877304]

34. Willi C, Bodenmann P, Ghali WA, Faris PD, Cornuz J. Active smoking and the risk of type 2 diabetes: a systematic review and meta-analysis. J Am Med Assoc 2007 Dec 12;298(22):2654-2664. [doi: 10.1001/jama.298.22.2654] [Medline: 18073361]

35. Kim HS, Jeong HS. A nurse short message service by cellular phone in type-2 diabetic patients for six months. J Clin Nurs 2007 Jun;16(6):1082-1087. [doi: 10.1111/j.1365-2702.2007.01698.x] [Medline: 17518883]

36. Kim CS, Park SY, Kang JG, Lee SJ, Ihm SH, Choi MG, et al. Insulin dose titration system in diabetes patients using a short messaging service automatically produced by a knowledge matrix. Diabetes Technol Ther 2010 Aug;12(8):663-669. [doi: 10.1089/dia.2010.0031] [Medline: 20615108]

37. Stone RA, Rao RH, Sevick MA, Cheng C, Hough LJ, Macpherson DS, et al. Active care management supported by home telemonitoring in veterans with type 2 diabetes: the DiaTel randomized controlled trial. Diabetes Care 2010 Mar;33(3):478-484 [FREE Full text] [doi: 10.2337/dc09-1012] [Medline: 20009091]

38. Bujnowska-Fedak MM, Puchała E, Steciwko A. The impact of telehome care on health status and quality of life among patients with diabetes in a primary care setting in Poland. Telemed J E Health 2011 Apr;17(3):153-163. [doi: 10.1089/tmj.2010.0113] [Medline: 21375410]

39. Quinn CC, Shardell MD, Terrin ML, Barr EA, Ballew SH, Gruber-Baldini AL. Cluster-randomized trial of a mobile phone personalized behavioral intervention for blood glucose control. Diabetes Care 2011 Sep;34(9):1934-1942 [FREE Full text] [doi: 10.2337/dc11-0366] [Medline: 21788632]

40. Tang PC, Overhage JM, Chan AS, Brown NL, Aghighi B, Entwistle MP, et al. Online disease management of diabetes: engaging and motivating patients online with enhanced resources-diabetes (EMPOWER-D), a randomized controlled trial. 
J Am Med Inform Assoc 2013 May 1;20(3):526-534 [FREE Full text] [doi: 10.1136/amiajnl-2012-001263] [Medline: 23171659]

41. Steventon A, Bardsley M, Doll H, Tuckey E, Newman SP. Effect of telehealth on glycaemic control: analysis of patients with type 2 diabetes in the Whole Systems Demonstrator cluster randomised trial. BMC Health Serv Res 2014;14:334 [FREE Full text] [doi: 10.1186/1472-6963-14-334] [Medline: 25100190]

42. Waki K, Fujita H, Uchimura Y, Omae K, Aramaki E, Kato S, et al. DialBetics: a novel smartphone-based self-management support system for type 2 diabetes patients. J Diabetes Sci Technol 2014 Mar 13;8(2):209-215 [FREE Full text] [doi: 10.1177/1932296814526495] [Medline: 24876569]

43. Zhou P, Xu L, Liu X, Huang J, Xu W, Chen W. Web-based telemedicine for management of type 2 diabetes through glucose uploads: a randomized controlled trial. Int J Clin Exp Pathol 2014;7(12):8848-8854 [FREE Full text] [Medline: 25674254]

44. Nicolucci A, Cercone S, Chiriatti A, Muscas F, Gensini G. A randomized trial on home telemonitoring for the management of metabolic and cardiovascular risk in patients with type 2 diabetes. Diabetes Technol Ther 2015 Aug;17(8):563-570. [doi: 10.1089/dia.2014.0355] [Medline: 26154338]

45. Kardas P, Lewandowski K, Bromuri S. Type 2 diabetes patients benefit from the COMODITY12 mHealth system: results of a randomised trial. J Med Syst 2016 Dec;40(12):259. [doi: 10.1007/s10916-016-0619-x] [Medline: 27722974]

46. Lim S, Kang SM, Kim KM, Moon JH, Choi SH, Hwang H, et al. Multifactorial intervention in diabetes care using real-time monitoring and tailored feedback in type 2 diabetes. Acta Diabetol 2016;53:189-198. [doi: 10.1007/s00592-015-0754-8] [Medline: 25936739]

47. Liu CT, Yeh YY, Lee TI, Li YC. Observations on online services for diabetes management. Diabetes Care 2005 Nov;28(11):2807-2808. [Medline: 16249564]

48. Faridi Z, Liberti L, Shuval K, Northrup V, Ali A, Katz DL. Evaluating the impact of mobile telephone technology on type 2 diabetic patients' self-management: the NICHE pilot study. J Eval Clin Pract 2008 Jun;14(3):465-469. [doi: 10.1111/j.1365-2753.2007.00881.x] [Medline: 18373577]

49. Kim H, Song MS. Technological intervention for obese patients with type 2 diabetes. Appl Nurs Res 2008 May;21(2):84-89. [doi: 10.1016/j.apnr.2007.01.007] [Medline: 18457747]

50. McMahon GT, Gomes HE, Hickson Hohne S, Hu TM, Levine BA, Conlin PR. Web-based care management in patients with poorly controlled diabetes. Diabetes Care 2005 Jul;28(7):1624-1629 [FREE Full text] [Medline: 15983311]

51. Takenga C, Berndt R, Musongya O, Kitero J, Katoke R, Molo K, et al. An ICT-based diabetes management system tested for health care delivery in the African context. Int J Telemed Appl 2014;2014:437307 [FREE Full text] [doi: 10.1155/2014/437307] [Medline: 25136358]

52. Yoo HJ, Park MS, Kim TN, Yang SJ, Cho GJ, Hwang TG, et al. A ubiquitous chronic disease care system using cellular phones and the internet. Diabet Med 2009 Jun;26(6):628-635. [doi: 10.1111/j.1464-5491.2009.02732.x] [Medline: 19538239]

53. Yoon KH, Kim HS. A short message service by cellular phone in type 2 diabetic patients for 12 months. Diabetes Res Clin Pract 2008 Feb;79(2):256-261. [doi: 10.1016/j.diabres.2007.09.007] [Medline: 17988756]

54. Stratton IM, Adler AI, Neil HA, Matthews DR, Manley SE, Cull CA, et al. Association of glycaemia with macrovascular and microvascular complications of type 2 diabetes (UKPDS 35): prospective observational study. Br Med J 2000 Aug 12;321(7258):405-412 [FREE Full text] [Medline: 10938048]

55. Pal K, Eastwood SV, Michie S, Farmer A, Barnard ML, Peacock R, et al. Computer-based interventions to improve self-management in adults with type 2 diabetes: a systematic review and meta-analysis. Diabetes Care 2014 Jun;37(6):1759-1766. [doi: 10.2337/dc13-1386] [Medline: 24855158]
Abbreviations
BMI: body mass index
CG: control group
$\mathbf{H b A}_{1 \mathbf{c}}$ : glycated hemoglobin
IG: intervention group
RCT: randomized controlled trial
T2DM: type 2 diabetes mellitus
WMD: weighted mean difference 
Edited by G Eysenbach; submitted 14.10.17; peer-reviewed by C Frith, $R$ Turner, A Pathanasethpong; comments to author 09.12.17; revised version received 28.02.18; accepted 17.03.18; published 07.05.18

Please cite as:

Shen Y, Wang F, Zhang X, Zhu X, Sun Q, Fisher E, Sun X

Effectiveness of Internet-Based Interventions on Glycemic Control in Patients With Type 2 Diabetes: Meta-Analysis of Randomized Controlled Trials

J Med Internet Res 2018;20(5):e172

URL: http://www.jmir.org/2018/5/e172/

doi: 10.2196/jmir.9133

PMID: 29735475

(C) Ying Shen, Fengbin Wang, Xing Zhang, Xiaorou Zhu, Qiudan Sun, Edwin Fisher, Xinying Sun. Originally published in the Journal of Medical Internet Research (http://www.jmir.org), 07.05.2018. This is an open-access article distributed under the terms of the Creative Commons Attribution License (https://creativecommons.org/licenses/by/4.0/), which permits unrestricted use, distribution, and reproduction in any medium, provided the original work, first published in the Journal of Medical Internet Research, is properly cited. The complete bibliographic information, a link to the original publication on http://www.jmir.org/, as well as this copyright and license information must be included. 